\title{
Contamination vs. Harm-Relevant outcome expectancies and covariation bias in spider phobia.
}

Citation for published version (APA):

de Jong, P. J., \& Peters, M. L. (2007). Contamination vs. Harm-Relevant outcome expectancies and covariation bias in spider phobia. Behaviour Research and Therapy, 45, 1271-1284. https://doi.org/10.1016/j.brat.2006.09.007

Document status and date:

Published: 01/01/2007

DOI:

10.1016/j.brat.2006.09.007

Document Version:

Publisher's PDF, also known as Version of record

Document license:

Taverne

Please check the document version of this publication:

- A submitted manuscript is the version of the article upon submission and before peer-review. There can be important differences between the submitted version and the official published version of record.

People interested in the research are advised to contact the author for the final version of the publication, or visit the DOI to the publisher's website.

- The final author version and the galley proof are versions of the publication after peer review.

- The final published version features the final layout of the paper including the volume, issue and page numbers.

Link to publication

\footnotetext{
General rights rights.

- You may freely distribute the URL identifying the publication in the public portal. please follow below link for the End User Agreement:

www.umlib.nl/taverne-license

Take down policy

If you believe that this document breaches copyright please contact us at:

repository@maastrichtuniversity.nl

providing details and we will investigate your claim.
}

Copyright and moral rights for the publications made accessible in the public portal are retained by the authors and/or other copyright owners and it is a condition of accessing publications that users recognise and abide by the legal requirements associated with these

- Users may download and print one copy of any publication from the public portal for the purpose of private study or research.

- You may not further distribute the material or use it for any profit-making activity or commercial gain

If the publication is distributed under the terms of Article $25 \mathrm{fa}$ of the Dutch Copyright Act, indicated by the "Taverne" license above, 


\title{
Contamination vs. harm-relevant outcome expectancies and covariation bias in spider phobia
}

\author{
Peter J. de Jong ${ }^{\mathrm{a}, *}$, Madelon L. Peters ${ }^{\mathrm{b}}$ \\ a Department of Developmental and Clinical Psychology, University of Groningen, Grote Kruisstraat 1/2, 9712 TS Groningen, \\ The Netherlands \\ ${ }^{\mathrm{b}}$ Department of Medical, Clinical, and Experimental Psychology, Maastricht University, The Netherlands
}

Received 17 January 2006; received in revised form 26 August 2006; accepted 12 September 2006

\begin{abstract}
There is increasing evidence that spiders are not feared because of harmful outcome expectancies but because of disgust and contamination-relevant outcome expectancies. This study investigated the relative strength of contamination- and harm-relevant UCS expectancies and covariation bias in spider phobia. High $(n=25)$ and low $(n=24)$ spider fearful individuals saw a series of slides comprising spiders, pitbulls, maggots, and rabbits. Slides were randomly paired with either a harm-relevant outcome (electrical shock), a contamination-related outcome (drinking of a distasting fluid), or nothing. Spider fearful individuals displayed a contamination-relevant UCS expectancy bias associated with spiders, whereas controls displayed a harm-relevant expectancy bias. There was no evidence for a (differential) postexperimental covariation bias; thus the biased expectancies were not robust against refutation. The present findings add to the evidence that contamination ideation is critically involved in spider phobia.
\end{abstract}

(C) 2006 Elsevier Ltd. All rights reserved.

Keywords: Disgust; Expectancy bias; Covariation bias; Phobia

A phobic stimulus can be conceptualised as a danger signal (e.g., Reiss, 1980, 1991), a predictor that something terrifying will occur following encounters with the phobic stimulus (e.g., "the spider will kill me" Arntz, Lavy, van den Berg, \& van Rijsoort, 1993). One explanation for the persistence of this type of danger expectancies could be that phobic individuals tend to overestimate the predictive relationship between phobic stimuli (CS) and aversive outcomes (UCS) (UCS expectancy bias; Davey, 1992). In line with this, several studies using various methodological approaches, and focusing on various fears (e.g., spider phobia, snake phobia, panic disorder, flight phobia), consistently showed that high fear individuals reported inflated expectancies of aversive outcomes following the presentation of fear-relevant stimuli (e.g., de Jong \& Merckelbach, 2000; Diamond, Matchett, \& Davey, 1995; McNally \& Heatherton, 1993; Wiedemann, Pauli, \& Dengler, 2001), whereas such inflated expectancies have been found to be absent in successfully treated individuals (Van Overveld, de Jong, Huijding, \& Peters, 2006).

\footnotetext{
*Corresponding author.

E-mail address: p.j.de.jong@rug.nl (P.J. de Jong).
} 
The tendency in high fear individuals towards expecting phobic stimuli to be followed by aversive outcomes (i.e., UCS expectancy bias) will logically motivate these people to avoid (and/or escape from) encounters with phobic stimuli. Accordingly, it has been found that danger expectancies were predictive of subsequent avoidance behaviour (e.g., Jones \& Menzies, 2000; Whittal \& Goetsch, 1997). Sustaining the causative role of danger expectancies, it has been shown that experimentally induced threat expectancies contribute to behavioural avoidance (Boston \& Sharpe, 2005). In its turn, avoidance of encounters with phobic stimuli will hinder extinction of fear, as such behaviours deprive fearful individuals from corrective experiences. Interestingly, there is also evidence that even when people cannot avoid or escape potentially correcting encounters with phobic stimuli, strong prior expectancies may be relatively immune to corrective information. That is, a series of illusory correlation (IC) experiments provided evidence to suggest that high fear individuals continue to expect aversive outcomes on fear-relevant trials despite the fact that in a typical IC experiment, the objective contingencies between the various categories of stimuli (e.g., slides of spiders, weapons, or flowers) and outcomes (e.g., shock, siren, or nothing) are objectively random (e.g., 1/3) (e.g., de Jong, Merckelbach, \& Arntz, 1991; de Jong \& Merckelbach, 2000; Pauli, Montoya, \& Martz, 2001).

Moreover, it has been found that high fear individuals also post-experimentally tend to overestimate the veridical covariation between feared stimuli and aversive outcomes (Cavanagh \& Davey, 2000; Davey \& Dixon, 1996; de Jong, Merckelbach, \& Arntz, 1995; Tomarken, Mineka, \& Cook, 1989; Tomarken, Sutton, \& Mineka, 1995). This a posteriori overestimation of the actual CS-UCS contingency has been termed covariation bias (Tomarken et al., 1989). Underlining the clinical significance of this type of associative bias, (residual) post-treatment covariation bias was found to be a powerful predictor of the return of fear following successful exposure treatment (de Jong, van den Hout, \& Merckelbach, 1995).

Thus far, studies on fear-relevant UCS expectancy bias and covariation bias primarily focused on harm/ pain-relevant outcome associations. This approach logically followed from the conceptualisation of small animal phobias (such as spider phobia) in terms of a predator-defense model (e.g., Öhman, Dimberg, \& Öst, 1985). However, there is increasing evidence that small animal phobias might be more efficiently conceptualised in terms of a disease-avoidance model (Matchett \& Davey, 1991; de Jong \& Muris, 2002). Following this model, fears of low-predation fear-relevant animals arise from people's tendency to associate these animals with outcomes indicating contamination or disease rather than with outcomes related to the animals' predatory properties (e.g., injuries that would result from being bitten) (e.g., Davey, 1994). In line with this, Davey and colleagues recently showed that in the context of a hypothetical conditioning experiment nonselected individuals selectively associated low predation animals (e.g., maggot, cockroach) with a contamination-relevant UCS (drinking a nauseating fluid), whereas participants typically expected a harmrelevant UCS (electrical shock) following predatory animals (e.g., lion) (Davey, Cavanagh, \& Lamb, 2003).

As a first exploration of the role of harm/pain-relevant versus contamination-relevant UCS representations in small animal phobias, van Overveld and colleagues recently exposed high and low spider fearful individuals to a similar 'thought-experiment' procedure, thereby adding spiders as a separate category of animals in the experimental design (Van Overveld, de Jong, \& Peters, 2006). Participants' a priori expectancies showed that spiders were associated with both types of aversive UCSs, but significantly stronger so in the high fear group. Interestingly, the expectancy bias toward contamination-relevant consequences was the single best predictor of spider fear. Hence these findings provide preliminary support for the idea that contamination rather than harm/pain-relevant preoccupations are critically involved in spider fear (cf. de Jong \& Muris, 2002) and are thus consistent with a disease-avoidance conceptualisation of spider fear. Note in passing that a diseaseavoidance conceptualization of spider distress does not dispute that fear is the dominant response to spiders (e.g., Sawchuk, Lohr, Westendorf, Meunier, \& Tolin, 2002), but implies that the focus of fear involves the probability of unwanted contact with a potential "contaminant" rather than the probability of being bitten and getting injured (e.g., Huijding \& de Jong, in press).

The present study was designed to further corroborate the preliminary findings concerning the role of contamination-relevant outcome expectancies in fear of spiders. Therefore, the first aim of this study was to test the robustness of these earlier findings and to see whether a similar pattern of outcome expectancies would emerge during actual encounters with spider stimuli. Following this, the present study investigated spider fearful individuals' outcome expectancies when being involved in an actual illusory correlation experiment, rather than in an imaginary experiment as was used by Van Overveld et al. (2006). The second aim of the study 
was to explore whether initial spider-harm/pain and spider-contamination expectancies vary with respect to their sensitivity to corrective experiences. More specifically, we examined to what extent differential outcome expectancies are maintained after extensive experience indicating random pairings of stimuli and outcomes. The relative (in)sensitivity to disconfirming information may provide important clues with respect to the strength (importance) of contamination-relevant and harm/pain-relevant UCS representations in spider phobia. As a third issue we tested the relationship between contamination and harm-related associative biases and phobic avoidance behaviour, in an attempt to explore further the relative importance of contamination versus harm/pain-related preoccupations in spider fear.

To test whether inflated associative biases in high fearful individuals (if present) are specific for spiders or represent a generally enhanced harm and/or contamination-relevant UCS expectancy bias, we included two additional categories of fear-relevant animals in the design. More specifically, in accordance with the study of Van Overveld et al. (2006) we included a category of low-predation contamination-relevant animals (maggots) and a category of high-predation harm/pain-relevant animals (pit bull terriers) (see also Davey et al., 2003). This particular design also allowed to see whether we could replicate the basic findings of Davey et al. (2003) that people generally expect predatory animals (pit bull) to be followed by harm-relevant outcomes (shock), and low-predatory animals (maggot) by contamination-relevant outcomes (drinking a nauseating fluid). Moreover, it provided the opportunity to test the important issue to what extent these initial selective associations are resistant to corrective information, and whether people also display a bias to retrospectively overestimate the actual contingency between a particular type of animal and a particular type of outcome (i.e., covariation bias).

\section{Methods}

Participants: Participants were 25 highly spider fearful and 24 explicitly nonfearful women. They were selected from a larger sample of 1st year psychology students of the University of Groningen $(N=435)$ on the basis of their scores on the fear of spiders questionnaire (FSQ; Szymanski \& O'Donohue, 1995; Muris \& Merckelbach, 1996). From those who initially indicated to be willing to participate in further research, we approached 26 women from the $10 \%$ highest scoring individuals and 26 women from the $10 \%$ lowest scoring individuals. Eventually 1 high fear and 2 low fear individuals refused to participate in the present experiment. Mean scores on the FSQ was $5.2(\mathrm{SD}=8.3)$ for the low fear group and $77.2(\mathrm{SD}=21.8)$ for the high fear group $[t(47)=15.1, p<.001]$. The FSQ scores of the high fear group were similar to those reported for treatment seeking samples (e.g., de Jong \& Merckelbach, 2000) and slightly higher than the scores that are reported for other analogue groups (e.g., Tolin, Lohr, Sawchuk, \& Lee (1997); de Jong, Peters, \& Vanderhallen, 2002). Participants received course credits for their participation in the present experiment.

\section{Apparatus and stimulus materials}

Illusory correlation paradigm: Four categories of slides were used in the present illusory correlation design: six different slides depicting a prototypical safe animal (i.e., rabbits), six slides depicting a prototypical lowpredation, disgusting animal (i.e., maggots), six slides depicting a fierce, harm-related animal (i.e., pit bulls), and six slides depicting spiders. ${ }^{1}$ The slides were projected onto a white screen $(80 \times 120 \mathrm{~cm})$, approx. $3 \mathrm{~m}$ in front of the participants. A computer-controlled beamer was used for stimulus presentation. Three types of outcomes occurred during the experiment. A $500 \mathrm{~ms}$ electrical shock was used as a symbolic representation of harm-relevant outcomes; drinking $5 \mathrm{ml}$ tween-20 solution (i.e., polysorbate 20 , an innocent but bad tasting fluid; e.g., Baeyens, Crombez, De Houwer, \& Eelen, 1996) at a concentration of $5 \mathrm{ml} /$ liter water was used as a symbolic representation of contamination-relevant outcomes; whereas "nothing" was used as a safe outcome. Electrical shocks (ac) were delivered from a Psylab shock generator (0-10 mA) and administered to the middle finger of the nondominant hand via two electrodes ( $2 \mathrm{~mm}$ diameter). The tween-20 solution was distributed via

\footnotetext{
${ }^{1}$ The spider slides that were used in the present study were the same as were used in previous covariation bias research in our lab (e.g., de Jong et al., 1995). None of the spiders were depicted as especially disgusting or physically threatening/fierce. Slides (*.jpg) can be obtained from the first author.
} 
a dispenser that had to be pressed two times to fill a $10 \mathrm{ml}$ measuring glass with $5 \mathrm{ml}$ of the solution. A pilot study using unselected participants $(N=52)$ confirmed that drinking $5 \mathrm{ml}$ of this solution (in the context of a hypothetical conditioning experiment) was strongly associated with disgust (mean VAS rating on a scale ranging from not disgusting at all $=0$ to extremely disgusting $=100$ was 66.5 [SD $=27.2]$ ).

Participants indicated their outcome expectancies on a trial by trial basis after each slide presentation via a response box that was connected to a personal computer (Pauli, Montoya, \& Martz, 1996). In addition, participants rated post-experimentally the covariation estimates for all stimulus/outcome combinations on VASs. We measured on-line expectancies as well as post-experimental covariation estimates since previous research revealed dissociations between both indices of associative bias. For example, post-experimental covariation bias has been found even when inflated on-line expectancies were already extinguished, suggesting that covariation bias is not simply a continuation of a pre-experimental expectancy bias (e.g., Amin \& Lovibond, 1997).

Behavioral approach task (BAT): The BAT is a widely used instrument to assess the degree of avoidance for specific stimuli such as spiders (Arntz et al., 1993; de Jong, Vorage, van den Hout, 2000). Participants had to approach a medium-sized common house spider (Tegenaria atrica) in eight steps, from looking at a spider in a closed jar to having a spider walk on their hands. The steps increased in difficulty and participants were informed that they could stop at any point. Participants' score was calculated by summing the amount of actual steps taken on the BAT scale ranging from $0(=$ distance to spider is $3 \mathrm{~m}$ ) to 8 (= spider on hand). Thus, high BAT-scores represent low avoidance of spiders.

\section{Procedure}

During the experiment, participants were seated in front of a table in a sound attenuated room. A one-way screen separated the experimental and the registration room. Before the experiment proper, shock intensity level was determined using a shock work-up procedure. Electrical current was increased stepwise until the participants indicated that the shock was definitely uncomfortable but not painful. Following the procedure that was also used in previous studies on covariation bias (e.g., Tomarken et al., 1989), participants were instructed that it was their task to determine the relationship between categories of slides and outcomes. They were explained that after the extensive series of slides they would be invited to complete a questionnaire concerning the relationship between slides and outcomes. In addition, they were explained that they had to indicate outcome expectancies on a trial-by-trial bias (cf. de Jong et al., 1995). Therefore, they were instructed to indicate their outcome expectancy after each slide by pressing the corresponding button on the response box (cf. Pauli, Wiedemann, \& Montoya, 1998). It was stressed that their choice had no influence on the actual outcomes. They were informed that after indicating their outcome expectancy via pressing the response box, one of three possible instructions/ messages would occur on the screen: (i) refill the measuring glass and drink the fluid; (ii) press the button to administer an electrical shock; (iii) nothing will happen. To familiarize participants with this procedure as well as with the respective outcomes, they were invited to (i) push the "shock" button one time before the experiment started (thereby administering themselves a shock after a $500 \mathrm{~ms}$ delay), and (ii) to fill one glass and drink the solution before the experiment proper.

During the experiment, the outcome-relevant instructions were followed after a fixed $6 \mathrm{~s}$ interval (a time interval that pilot work has shown to be sufficient to execute the various outcome-relevant instructions) by a message on the screen that instructed participants to press a button to continue the experiment. Intertrial intervals ranged from 5 to $15 \mathrm{~s}$. Across all trials, each stimulus-outcome combination occurred equally often. Thus, the conditional probability of any outcome given the prior occurrence of any category of slide was $1 / 3$, the probability of occurrence of each type of slide was $1 / 4$, and that of each outcome $1 / 3$. Stimulus-outcome combinations were randomly distributed across trials, with the restriction that on two successive trials no identical stimulus-outcome combinations occurred. To cancel out order effects, six different sequences were used that were balanced across groups. Participants were exposed to 72 slides of 6-s duration. At the end of the experiment, participants were asked to estimate the occurrence of each outcome given the prior occurrence of each slide type. For these covariation estimates, $100-\mathrm{mm}$ visual analogue scales (VASs) were used ranging from $0 \%$ to $100 \%$. For each outcome, the 4 pertinent VASs were presented on the same sheet. The order of VASs was fixed. Finally, participants underwent the BAT. 


\section{Data reduction}

Initial expectancies: To investigate initial expectancies, for both groups the percentage of participants was computed that indicated to expect a shock, the fluid, or nothing on the first trial of each class of slides.

On-line expectancies: For each type of slides, the percentage of trials was computed on which participants indicated to expect a particular outcome (i.e., harm-relevant, disgust-relevant, and safe outcomes), in blocks of 6 trials (displaying this particular slide). Following the procedure of Van Overveld, de Jong, Huijding et al. (2006) we then computed difference scores by subtracting the expectation of nothing from the expectation of an aversive consequence (harm-relevant: expectation of shock minus expectation of nothing; contaminationrelevant: expectation of fluid minus expectation of nothing) to facilitate subsequent analyses and retain optimal power.

Post-experimental reported contingency estimates: Similar to the on-line expectancies, we first computed difference scores by subtracting the expectation of nothing from the expectation of an aversive consequence (harm-relevant: expectation of shock minus expectation of nothing; contamination-relevant: expectation of fluid minus expectation of nothing) to facilitate subsequent analyses.

\section{Results}

\section{$B A T$}

Mean BAT scores were 4.1 $(\mathrm{SD}=1.9)$ and $7.6(\mathrm{SD}=0.7)$ for the high and low fear groups, respectively $[t(47)=8.3, p<.001]$.

\section{Initial outcome expectancies}

Pitbulls, maggots, and rabbits: Initial outcome expectancies as a function of animal type are displayed in Fig. 1. In line with the predictions, sign tests indicated that: (i) participants more often expected the

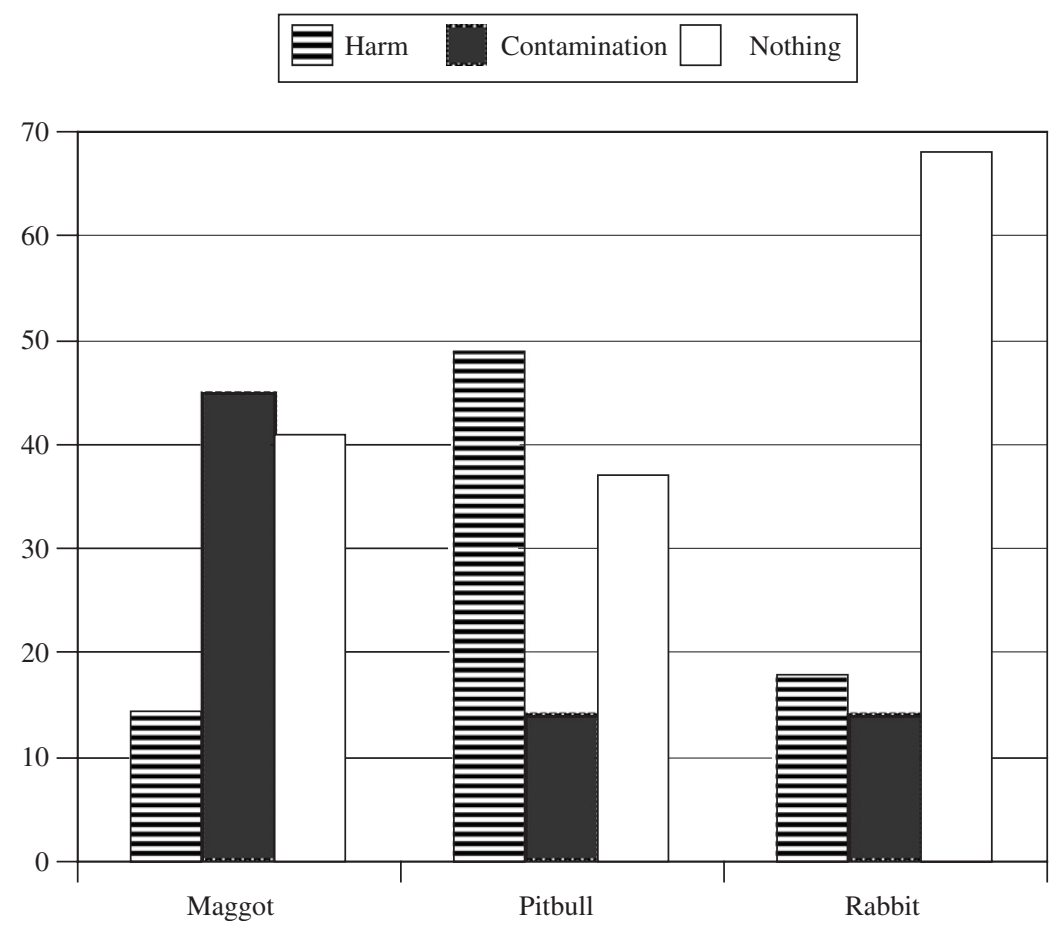

Fig. 1. Percentage of participants expecting a particular outcome (harm-relevant, contamination-relevant, or nothing) during the first trial, for each category of stimuli (pitibull, maggot, rabbit). 
contamination-relevant fluid after the first maggot slide (45\%) than after both the first pit bull (14\%) and the first rabbit $(14 \%)$ slides, $p$ 's $<.001$, whereas the percentage of participants expecting the fluid outcome following the first maggot was significantly higher than chance $\left[\chi^{2}(1)=2.95, p<.05\right]$; (ii) participants more often expected the harm-relevant shock after the first pit bull slide $(49 \%)$ than after both the maggot $(14 \%)$ and rabbit $(18 \%)$ slides, $p$ 's $<.005$, whereas the percentage of participants expecting the shock outcome following the first pit bull was also significantly higher than chance $\left[\chi^{2}(1)=5.40, p<.05\right]$; (iii) participants more often expected the safe outcome (nothing) after the first rabbit slide $(68 \%)$ than after both the maggot $(41 \%)$ and pit bull $(38 \%)$ slides, $p$ 's $<.05$, whereas the percentage of participants expecting the safe outcome following the first rabbit was significantly higher than chance $\left[\chi^{2}(1)=25.51, p<.05\right]$; (iv) participants more often expected the fluid than shock after the first maggot slide $(p=.005)$, more often expected the shock than fluid after the first dog slide $(p=.002)$, whereas no differences were evident for the first rabbit slide in this respect $(p>.1)$. Meanwhile, it should be noted that the number of participants expecting the fluid following the maggot did not differ from the number of individuals indicating to expect nothing $(p>.2)$; in a similar vein it appeared that the number of participants expecting a shock following the dog slide did not significantly differ from the number of participants indicating to expect nothing $(p>.1)$. (iv) Finally, indicating that the pattern of differential outcome expectancies for nonfeared animals is similar for high and low spider fearful individuals, Mann-Whitney $U$ tests indicated that the initial outcome expectancies (i.e., fluid, shock, or nothing) for maggots, pitbulls, or rabbits, did not significantly differ between high and low spider fearful individuals $(p$ 's $>.1)$.

Spiders: For both the high and low fear groups, outcome expectancies on the first spider trial are depicted in Fig. 2. High fear individuals more often expected the contamination-relevant fluid outcome during the first spider slide than low fear individuals $\left[\chi^{2}(1)=5.4, p=.02\right]$. There was no difference between the high and low fear group with respect to the percentage of individuals expecting a shock outcome during the first spider trial $\left[\chi^{2}(1)=0.9, p=.32\right]$. In line with previous research, the percentage of individuals expecting that the first spider would not be followed by an aversive outcome (i.e., neutral/safe outcome) tended to be smaller in the high fear group than in the low fear group $\left[\chi^{2}(1)=-1.6, p=.06\right]$.

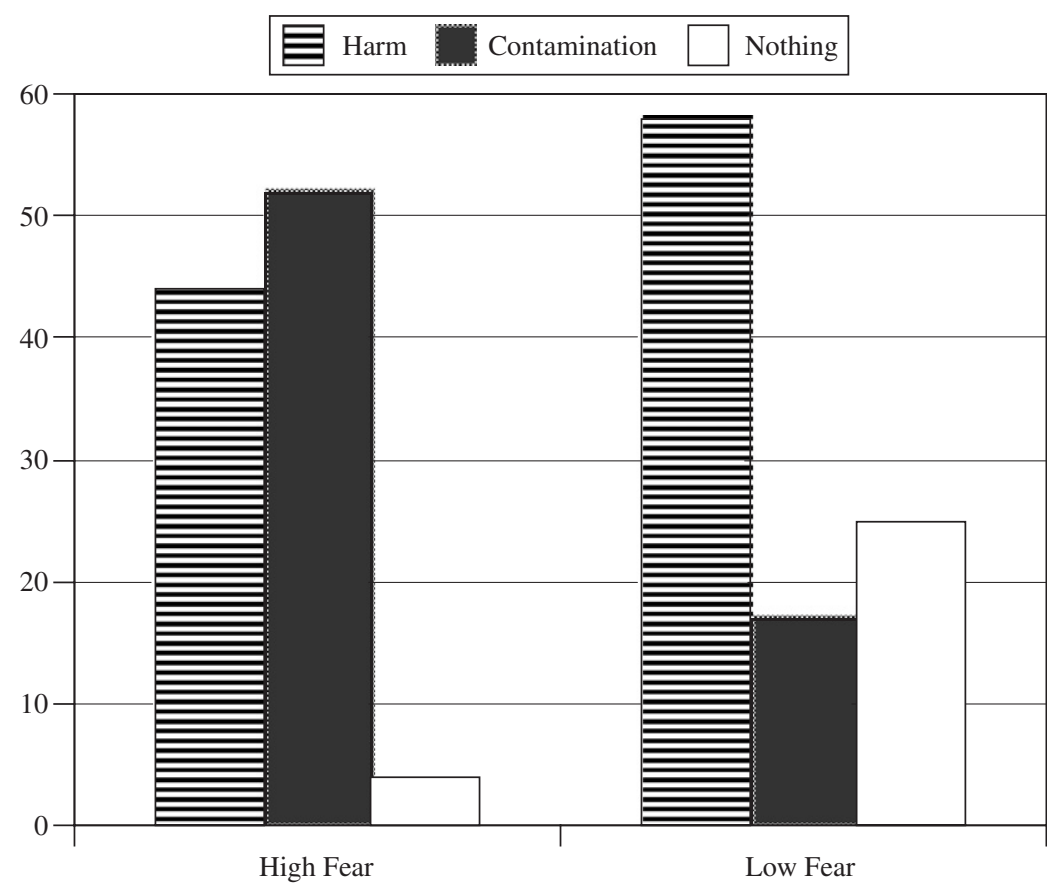

Fig. 2. Percentage of participants expecting a particular outcome (harm-relevant, contamination-relevant, or nothing) during the first spider slide as a function of spider fear (high vs. low). 
Within group comparisons indicated that for the high fear group participants' pattern of outcome expectancies deviated significantly from an equal distribution across the three types of outcomes $\left[\chi^{2}(2)=7.28\right.$, $p<.05]$. The percentage of individuals expecting the safe outcome (nothing) was significantly lower than could be expected on the basis of chance (i.e., 33,3\%) $\left[\chi^{2}(1)=7.22, p<.05\right]$. Put differently, high fearful individuals were shown to be generally characterized by a tendency to expect aversive rather than safe outcomes on the first spider trial. The percentage of individuals expecting the fluid outcome was marginally higher than could be expected on the basis of chance $\left[\chi^{2}(1)=2.4, p=.06\right]$, whereas the percentage of individuals expecting shock was not significantly different from $33.3 \%\left[\chi^{2}(1)=1.3, p=.13\right]$. Comparisons between outcomes indicated that high fearful individuals more often expected shock $(p=.02)$, or fluid $(p=.01)$ than nothing after the first spider slide (see also Fig. 2), whereas no significant difference was evident between the number of individuals expecting the fluid or shock outcome $(p>9)$.

Also for the low fear individuals the pattern of outcome expectancies deviated significantly from an equal distribution across the three types of outcomes $\left[\chi^{2}(2)=7.00, p<.05\right]$. In contrast to the high fearful group, the percentage of low fearful individuals expecting the safe outcome (nothing) was not significantly different from the percentage that could be expected on the basis of chance $\left[\chi^{2}(1)=0.75, p=.38\right]$. The percentage of individuals expecting the aversive contamination-relevant outcome was lower than could be expected on the basis of chance $\left[\chi^{2}(1)=3.00, p<.05\right]$. Meanwhile, the percentage of individuals expecting shock was found to be significantly higher than $33.3 \%\left[\chi^{2}(1)=6.75, p<.05\right]$. Comparisons between outcomes indicated that low fearful individuals more often expected the shock than the fluid outcome after the first spider slide $(p=.031)$, and showed a nonsignificant tendency to expect more often a shock than nothing $(p=.11)$. There was no difference between the number of low fear individuals expecting nothing or fluid $(p>.7)$.

\section{On-line outcome expectancies}

Pitbulls, maggots, and rabbits: On-line outcome expectancies are shown in Table 1. A 3 Animal (pit bull, maggot, rabbit) $\times 2$ Outcome (shock minus nothing, fluid minus nothing) $\times 3$ Block $\times 2$ Group (high vs. low fear) revealed that in general participants more often expected the safe than the aversive outcome, as was evidenced by the finding that the intercept was significantly smaller than zero $[F(1,47)=30.10, p<.05$, $\eta^{2}=.39$ ] (see also Table 1). There was a significant main effect of Animal indicating that this tendency varied across the three types of animals $\left[F(2,46)=6.80, p<.05, \eta^{2}=.23\right]$. Simple contrasts showed that participants less often expected a safe outcome on maggot than on rabbit trials $\left[F(1,47)=13.88, p<.05, \eta^{2}=.23\right]$, and less often on pit bull than on rabbit trials $\left[F(1,47)=7.52, \eta^{2}=.14\right]$, whereas there was a marginally significant tendency indicating that individuals generally expected less often a safe outcome on maggot than on pit bull trials $\left[F(1,47)=3.59, p=.06, \eta^{2}=.07\right]$. There was a nonsignificant tendency indicating that in general people more often expected the fluid than the shock outcome $\left[F(1,47)=2.93, p=.09, \eta^{2}=.06\right]$.

The Animal by Outcome interaction did not reach significance $\left[F(2,46)=1.82, p=.17, \eta^{2}=.07\right]$, thus there is no convincing evidence indicating that that during the experiment participants generally expected pitbulls to be followed by shock and maggots by the fluid. Meanwhile, the strength of the predicted pattern of differential outcome expectancies varied over blocks of trials, as was evidenced by a significant Animal by Outcome by

Table 1

Mean on-line outcome expectancies as a function of block of trials

\begin{tabular}{|c|c|c|c|c|c|c|c|c|c|c|c|c|}
\hline & \multicolumn{3}{|l|}{ Pit bull } & \multicolumn{3}{|c|}{ Maggot } & \multicolumn{3}{|l|}{ Rabbit } & \multicolumn{3}{|l|}{ Spider } \\
\hline & Shock & Fluid & Nothing & Shock & Fluid & Nothing & Shock & Fluid & Nothing & Shock & Fluid & Nothing \\
\hline \multicolumn{13}{|l|}{ Block } \\
\hline 1 & .24 & .37 & .39 & .22 & .43 & .35 & .23 & .18 & .59 & .29 & .33 & .38 \\
\hline 2 & .34 & .22 & .44 & .32 & .33 & .35 & .21 & .24 & .55 & .36 & .21 & .43 \\
\hline 3 & .32 & .25 & .43 & .26 & .37 & .37 & .24 & .28 & .48 & .34 & .27 & .39 \\
\hline Mean $^{\mathrm{a}}$ & .30 & $.28^{*}$ & $.42 *$ & $.27^{*}$ & .38 & .35 & $.23^{*}$ & $.23^{*}$ & $.54 *$ & .33 & $.27 *$ & $.40^{*}$ \\
\hline
\end{tabular}

*Denotes a significant difference from chance level $(p<.05)$.

${ }^{\mathrm{a}}$ To test whether for each of the animals the various outcome expectancies actually deviated from chance level (.333), mean expectancies were subjected to one sample $t$-tests. 
Block interaction $\left[F(4,44)=3.9, p<.05, \eta^{2}=.26\right]$. Subsequent analyses indicated that for the first block, the Animal by Outcome interaction was significant $\left[F(2,46)=6.76, p<.05, \eta^{2}=.23\right]$. In line with predictions, the differential outcome expectancies between rabbit and maggot trials were most pronounced for the expectancies of the fluid outcomes (see also Table 1) $\left[F(1,47)=11.64, p<.05 \eta^{2}=.20\right]$. Unexpectedly, the differential outcome expectancies between rabbit and pit bull trials was very similar, indicating that the difference between the outcome expectancies between pitbulls and rabbits was also most pronounced for the fluid outcomes $\left[F(1,47)=7.67, p<.05, \eta^{2}=.14\right]$. Accordingly, the pattern of outcome expectancies was very similar for pit bull and maggot trials $\left[F(1,47)=1.08, p=.30, \eta^{2}=.02\right]$. For the second and third block the Animal by Outcome interaction did not reach the conventional level of significance, $[F(2,46)=3.10, p=.06$ $\left.\eta^{2}=.12\right]$ and $\left[F(2,46)=1.67, p=.20 \eta^{2}=.07\right]$, respectively. So the differential outcome expectancies appeared to have been readily extinguished during the experiment. None of the effects differed between groups, so the pattern appeared independent of spider fear.

To test whether for each of the animals the various outcome expectancies actually deviated from chance level (.333), mean expectancies were subjected to one sample $t$-tests. The results are summarised in Table 1. Most important for the present context, the percentage of trials on which participants indicated to expect a safe outcome on trials depicting the safe animal (rabbit) was significantly higher than chance level, whereas for both aversive outcomes this percentage was significantly below chance level. Yet, nor the expectancies of fluid outcomes on maggot trials nor the expectancies of shock outcomes on pit bull trials was significantly different from chance (see Table 1).

Spiders: A 2 Outcome (shock minus nothing vs. fluid minus nothing) $\times 3$ Block $\times 2$ Group (high vs. low fear) ANOVA, revealed that in general participants more often expected the safe than the aversive outcome as was evidenced by the finding that the intercept was significantly smaller than zero $[F(1,47)=6.68, p<.05$, $\left.\eta^{2}=.12\right]$ (see also Table 1). There was no main effect of Group indicating that this effect was similar for both groups $\left[F(1,47)=.01 ; \eta^{2}<.01\right]$. In addition, there was no significant main effect of Outcome $[F(1,47)=2.47$, $\left.p=.12, \eta^{2}=.05\right]$, nor a Group by Outcome interaction $\left[F(1,47)=0.38 ; \eta^{2}<.01\right]$, indicating that irrespective of phobic fear, participants expected both types of aversive outcomes equally often to occur following spider slides. None of the other effects reached significance. To examine whether the outcome expectancies for spider trials deviated from chance (33 1/3\%), mean outcome expectancies were subjected to one-sample $t$-tests. The mean percentage of trials on which participants indicated to expect the safe outcome was significantly higher than $331 / 3 \%[t(48)=2.61, p<.05]$, whereas for fluid outcomes the percentage was significantly below $331 / 3$ $[t(48)=-3.23, p<.05]$. The percentage of trials on which people indicated to expect a shock outcome was on chance level $[t(48)=-0.23]$ (see also Table 1$)$.

\section{Post-experimental reported contingency estimates}

Pitbulls, maggots, and rabbits: For both groups, the post-experimental reported contingency estimates are shown in Table 2. A 3 Animal (pit bull, maggot, rabbit) $\times 2$ Outcome (harm minus nothing, fluid minus nothing) $\times 2$ Group (high vs. low fear) ANOVA showed a significant main effect of Animal $[F(2,46)=10.32$, $\left.p<.05, \eta^{2}=.31\right]$, indicating that there was a difference between the animals to which they were associated with either of the aversive consequences. This is displayed in Fig. 1, which shows that participants associated aversive consequences relatively strongly with pitbulls and maggots compared to rabbits. Although the pattern of covariation estimates was similar for both groups, a significant Animal by Group interaction $\left[F(2,46)=4.50, p<.05, \eta^{2}=.17\right]$ evidenced that the differential pattern of covariation estimates was most

Table 2

Mean (SD) post-experimental covariation estimates for high and low spider fearful individuals

\begin{tabular}{|c|c|c|c|c|c|c|c|c|}
\hline \multirow[t]{2}{*}{ Outcome } & \multicolumn{2}{|l|}{ Pit bull } & \multicolumn{2}{|l|}{ Maggot } & \multicolumn{2}{|l|}{ Rabbit } & \multicolumn{2}{|l|}{ Spider } \\
\hline & High & Low & High & Low & High & Low & High & Low \\
\hline Shock & 49 (17) & 49 (22) & 44 (19) & $44(20)$ & 32 (19) & 34 (18) & $43(22)$ & $48(16)$ \\
\hline Fluid & $47(24)$ & 41 (18) & $53(21)$ & $47(25)$ & $35(23)$ & $43(22)$ & 39 (23) & 43 (17) \\
\hline None & 33 (15) & 44 (17) & 37 (15) & $36(22)$ & $61(23)$ & $46(17)$ & $41(24)$ & 46 (18) \\
\hline
\end{tabular}


pronounced for the high fear group (see Table 2). The main effect of Outcome did not approach significance $\left[F(1,47)=0.78, \eta^{2}=.02\right]$ indicating that people do not generally associate the various animals with one of the aversive outcomes. As can be seen in Table 2, the pattern of findings seems to suggest that in line with the predictions, participants display selective pit bull-shock and maggot-fluid associations. However, the Animal by Outcome interaction did not approach the conventional level of significance $[F(2,46)=2.41, p=.10$, $\left.\eta^{2}=.10\right]$. Meanwhile, planned comparisons indicated that with respect to pitbulls and maggots the covariation estimates were significantly higher for aversive than for safe outcomes $(p$ 's $<.005)$, whereas, in contrast, for rabbits estimates were higher for safe than for aversive outcomes $(p<.01)$.

Spiders: For both high and low spider fearful individuals, postexperimental covariation estimates for spiders are shown in Table 2. A 2 Outcome (shock minus nothing vs. fluid minus nothing) $\times 2$ Group (high vs. low fear) ANOVA indicated that in general participants did not display a relatively strong association between spiders and aversive outcomes as was evidenced by the finding that the intercept did not differ from zero $\left[F(1,47)=0.01, \eta^{2}<.01\right]$. There was no significant main effect of Group $\left[F(1,47)=.01 ; \eta^{2}<.01\right]$, so this pattern was similar for high and low fearful individuals. Moreover the pattern was similar for both types of outcomes as there was neither a significant main effect of Outcome $\left[F(1,47)=1.55, p=.22, \eta^{2}=.03\right]$, nor a significant Outcome by Group interaction $\left[\mathrm{F}(1,47)=0.00, \eta^{2}<.01\right]$. Thus neither high nor low fearful individuals displayed a bias to post-experimentally overassociate the covariation between spider slides and harm or contamination-relevant outcomes.

\section{Relationship between initial, on-line, and post-experimental spider/outcome associations and fear of spiders}

A backward regression analysis was used to study the relative contributions of harm and contaminationrelated selective associations in predicting phobic avoidance behaviour. In the major analysis BAT-scores were used as the dependent variable, whereas initial and on-line outcome (harm and contamination) expectancies, as well as post-experimental reported harm-relevant and contamination-relevant covariation estimates were used as the predictor variables. The first equation (including all predictor variables) showed that initial disgust-relevant outcome expectancy was the only variable with significant independent predicting properties for individuals' level of approach behaviour $[\beta=-.43 ; p=.04$, ] (the negative $\beta$-value indicates that individuals who expected a disgust-relevant outcome following the first spider slide displayed less approach behaviour). In addition, initial disgust-relevant outcome expectancy was the only variable that remained in the final equation, indicating that initial disgust expectancy was also the only variable that had unique predicting properties regarding individuals' level of approach behaviour.

A similar regression analysis with the FSQ as the dependent variable provided similar results. The first equation showed that initial disgust-relevant outcome expectancy was the only variable with significant independent predicting properties for individuals' level of self-reported spider fear; in addition, initial disgustrelevant outcome expectancy was the only variable that remained in the final equation, indicating that only initial disgust expectancy had unique predicting properties regarding individuals' level of self-reported spider fear $[\beta=.49 ; p=.02]$.

\section{Discussion}

The major aim of the present study was to investigate the relative strength of contamination- and harm/ pain-relevant associative biases in spider phobia, and to see whether these associative biases are specific for spiders or represent a more generally enhanced tendency to (over)associate particular animals with harm and/ or contamination related outcomes. The main results can be summarised as follows: (i) spider fearful individuals were characterized by a spider-specific contamination-relevant initial UCS expectancy bias; (ii) consistent with a disease-avoidance conceptualisation of spider fear this initial contamination-relevant outcome expectancy bias was found to be the single best predictor of phobic avoidance behaviour; (iii) individuals' initial outcome expectancies appeared highly sensitive to disconfirming information and neither low nor high fearful participants showed a post-experimental bias to overestimate the covariation between spiders and harm- and/or contamination-relevant outcomes; (iv) meanwhile, irrespective of prior fear participants did show a post-experimental covariation bias between pitbulls/maggots and aversive outcomes; 
yet there was no convincing evidence to indicate that this covariation bias was outcome specific as was found for the initial outcome expectancies.

\section{Differential initial aversive outcome associations and fear of spiders}

The major aim of the present study was to explore the role of harm- vs. contamination-relevant outcome expectancies and covariation bias in spider phobia. Using the thought experiment procedure that was originally designed by McNally and Heatherton (1993), Van Overveld et al. (2006) recently showed that spider fearful individuals are characterized by a bias to a priori expect harm-relevant as well as contaminationrelevant UCSs following spider slides. Meanwhile, a relatively strong a priori expectancy of a contaminationrelevant outcome following spider slides differentiated best between high and low spider fearful individuals.

In line with these preliminary findings, the present experiment revealed that both high and low fearful individuals more often expected a harm-relevant (shock) than a safe (nothing) outcome after the first spider slide, whereas only high fearful individuals also more often expected a contamination-relevant than a harmrelevant (or safe) UCS following the first spider slide. Hence the present study underlines the robustness of the earlier findings of Van Overveld et al. (2006), and further corroborates these preliminary findings by showing that similar contamination-relevant outcome expectancies emerge when using an in vivo rather than an in vitro approach implying actual encounters with spider stimuli.

Interestingly, the high and low fearful group not only differed with respect to their initial danger expectancies but also with respect to their initial safety expectancies. The finding that the percentage of participants expecting that the first spider slide would be followed by the safe (nothing) outcome was marginally lower in the high fear group suggests that fearful individuals not only overestimate the occurrence of aversive, contamination related outcomes, but also underestimate safety upon confrontation with their phobic stimulus. Such an underestimation of safety may be an additional mechanism operating in a way to maintain phobic fear and avoidance. Future research is necessary to see whether this finding represents a robust phenomenon.

Consistent with the relative importance of contamination-relevant outcome expectancies in spider fear, initial contamination-relevant outcome expectancy for spider slides was the single best predictor of individuals' avoidance behaviour (i.e., BAT). This finding is in accordance with earlier research of Van Overveld et al. (2006), and in line with previous work using a vignette approach (de Jong \& Muris, 2002) showing that the disgust-evoking status of spiders was the single best predictor of spider phobia, whereas the independent contribution of the perceived probability of harm from spiders was found to be negligible. Together, these findings underline the relative importance of disgust and contamination-relevant outcome associations in the context of spider phobia. Apparently, irrespective of prior fear people generally associate spiders with harm-relevant outcomes, whereas typically high fearful individuals are (also) characterized by inflated contamination-relevant outcome associations related to spider stimuli.

It should be acknowledged that there may be a differential salience for the contamination-relevant outcome (i.e., the fluid) and the harm/pain related outcome (electric shock) due to the number of pre-exposures to the shock in order to establish individual tolerance levels. Such a differential salience may have influenced participants' pattern of outcome expectancies. However, since people generally tend to overassociate the contingency between salient stimuli (e.g., Hamilton \& Gifford, 1976), this would have biased fearful participants to overestimate the spider-shock rather than the spider-solution association. So it seems not very likely that the relatively strong tendency of fearful individuals to expect the contamination-relevant outcome following the first spider slide can be attributed to this potential differential salience between outcomes. It might actually have resulted in an underestimation of the spider-contamination association.

The results of the present study support the idea that the contamination-relevant associative bias in high fearful individuals reflects a bias that is specific for spiders rather than a generally enhanced bias to overassociate contamination-relevant outcomes with (disgust-relevant) animals in general. Only with respect to the contamination-relevant expectancies on spider trials differences emerged between high and low fearful individuals, whereas no between group differences were evident with respect to any of the other animal(contamination-relevant) outcome associations. Meanwhile, irrespective of spider fear, participants did show a general tendency towards expecting physically harmful rather than contamination-relevant outcomes 
associated with pitbulls (predatory animals), and with expecting contamination-relevant outcomes rather than harm-relevant outcomes associated with maggots (low-predation fear-relevant animal). Hence this pattern of findings corroborate earlier evidence indicating that various groups of animals are differentially associated with harm versus disgust related UCS expectancies (e.g., Davey et al., 2003; Van Overveld et al., 2006), and cast further doubt on the possibility that participants' pattern of UCS expectancies merely reflect an artefactual salience asymmetry between both types of aversive outcomes.

\section{Sensitivity to corrective information}

The on-line expectancy data revealed that the initial outcome expectancies are sensitive to corrective information. Participants' initial outcome expectancies on spider trials were readily corrected during the random stimulus-outcome pairings. For neither high nor low spider fearful individuals a differential pattern of on-line expectancies on spider trials emerged. In a similar vein, the differential outcome expectancies on the maggot, pit bull, and rabbit trials were strongly influenced by the random stimulus-outcome pairings. Although the pattern of mean on-line expectancies was similar to that of the initial expectancies, the pattern of differential aversive outcome expectancies was clearly attenuated and did no longer reach the conventional level of significance. Thus although participants entered the experiment with a differential expectancy bias, this bias appeared not particularly robust against refutation.

In a similar vein, participants' post-experimental covariation estimates for spider trials were close to the veridical covariation and no evidence emerged to indicate that spider fear was related to harm- or contamination-relevant covariation bias. These findings seem to indicate that individuals' biased spiderrelevant a priori outcome expectancies are highly sensitive to corrective information. Similarly, postexperimentally there was no longer evidence for differential associative biases to selectively overassociate maggots with a contamination-relevant UCS, and pitbulls with a harm-relevant UCS. Meanwhile, participants did show a bias to overassociate both types of aversive (fear-relevant) animals with aversive outcomes compared to rabbits. Yet, this bias was similar for both types of outcomes (i.e., harm-relevant vs. contamination-relevant). Hence this general covariation bias seems to reflect a rather general (or crude) tendency to retrospectively overestimate the covariation between aversive stimuli and aversive outcomes, that acts independently of the particular aspects or dimensions (e.g., "contamination" or "pain") that constitutes the aversiveness of a particular type of outcome.

The failure of the biased initial outcome expectancies on maggot, rabbit, and pit bull trials to survive disconfirmation might be due to the fact that the present participants represented an unselected sample with respect to fear of maggots and/or fear of pitbulls. It might well be that biased initial expectancies only survive extensive random stimulus-outcome pairings when stimuli are motivationally salient (e.g., highly feared). Consistent with such an explanation it has been shown in previous research that spider fearful individuals displayed inflated initial UCS expectancies for both weapons (or electrical outlets) and spiders, whereas postexperimentally these individuals only reported inflated covariation estimates for spiders but not for weapons/outlets (e.g., de Jong \& Merckelbach, 2000; de Jong et al., 1995; Kennedy, Rapee, \& Mazurski, 1997). Relatedly, the fact that the maggot and pit bull stimuli were not motivationally salient for the present participants (e.g., not highly feared) may also account for the present finding that a considerable percentage of participants indicated to expect a safe outcome on the first maggot and pit bull trials, whereas only a negligible percentage of high fearful individuals indicated to expect nothing on the first spider trial.

At first sight this explanation seems at odds with the findings with respect to the on-line and postexperimental covariation estimates pertaining to spider trials. However, there may be other reasons that may explain the absence of a spider-relevant covariation bias in spider fearful individuals. That is, the present experimental design differed in several important respects from the covariation bias paradigm that was originally designed by Tomarken et al. (1989). First, participants in the present study not only rated postexperimental covariation estimates but also indicated their on-line expectancies on a trial by trial basis. Hence it might be that the on-line judgment task has influenced the bias to retrospectively overestimate the covariation between spider-stimuli and aversive outcomes. However, the previous finding that individuals who were instructed to keep a running estimate during serially presented stimuli reported a stronger postexperimental illusory correlation between salient stimuli than individuals who merely had to report post- 
experimental covariation estimates (Arkes \& Harkness, 1983; exp 7), renders this possibility not very likely. In addition, several previous studies measuring on-line expectancies were successful in showing post-experimental covariation bias (e.g., de Jong et al., 1995; Pauli, Wiedemann, Dengler, \& Kühlkamp, 2001). However, further experiments including both a condition with and without participants reporting on-line expectancies is necessary to settle this issue more definitely.

Second, in the present study the aversive outcomes were administered by the participants themselves via drinking a glass of the distasting solution and via pressing a button to activate the shock generator instead of passively experiencing the outcomes as was the case in all previous studies. We eventually decided to using a self-administration procedure since a computer-controlled administration of the disgust-relevant outcome (e.g., via computerised injection of the fluid via a catheter in the mouth) appeared too invasive. Moreover, the present procedure most closely mimics the original procedure described in the thought experiment of Davey et al. (2003; " “...you may be asked to drink some of the fluid, which will make you feel ill and vomit immediately..."). Meanwhile, it can not be ruled out that this active involvement made the actual stimulus-outcome contingency more salient, thereby opposing the generation of illusory correlations. However, such an explanation of the absence of a fear relevant covariation bias seems not very convincing given that within the same experimental design a covariation bias did emerge between maggots/pitbulls and aversive outcomes.

Third, and perhaps most important, the present experiment included two aversive outcomes rather than one, and both types of outcomes appeared relevant for spiders. This characteristic (i.e., the presence of two competing prior expectancies of covariation) might have undermined the present experiment's sensitivity to detect harm- and/or contamination-relevant covariation biases related to spider stimuli (cf. de Jong et al., 1992). One way to explore this possibility would be to use type of outcome as a between subjects rather than a within subjects factor in the design of a future study. Finally, in contrast to previous studies, the present experiment included four different types of slides (animals) rather than three. One consequence of this procedure is that the base-rate of each of the stimulus/outcome combinations was reduced with approximately $27 \%$ (from $8 / 72$ to $6 / 72$ ). Previous studies have shown that increasing the sheer frequency of expected cooccurrences, results in stronger covariation bias effects (e.g., Pauli et al., 1996; Tomarken et al., 1989; exp. 3). Following this, it might be argued that lowering the frequency of expected stimulus/outcome combinations (as was implied in the current design) weakened the present covariation bias effects. One way to test this explanation would be to replicate the present study while restricting the number of slide categories to three rather than to four (e.g., mushroom, flower, and spider).

Alternatively, it might be the case that the present absence of a convincing spider-relevant covariation bias indicates that such a retrospective bias to overassociate phobic stimuli with particular UCS experiences is not a robust phenomenon and/or may not play a vital role in maintaining real-life spider phobia. That is, systematic avoidance of spiders may well imply that the corrective experiences received in the covariation procedure are rarely experienced by phobic individuals (cf. de Jong, Merckelbach, Bögels, \& Kindt, 1998). Accordingly initial expectancy biases may persist and continue to reinforce avoidance behaviour even though expectancy biases may be extinguished rather easily.

\section{Contamination-relevant outcome expectancies and fear of spiders}

Although the available evidence indicate that fear of spiders is related to contamination-relevant preoccupations, this does not explain how inflated contamination-relevant UCS expectancies may actually result in heightened fear levels. Moreover, it may raise the question why fears of other animals that also evoke contamination-relevant outcome expectancies, such as maggots, only very seldom reach the phobic range. One explanation might be that fear of spiders can be best conceptualised as a fear of involuntary physical contact with a disgusting stimulus (cf. de Jong et al., 2000). For animals such as maggots, worms, and snails the chances of involuntary and unexpected physical contact are negligible, as they are relatively immobile and/or do not tend to enter people's private territories. In contrast, spiders frequently cross the border of people's private living space and can move quickly. Therefore, the threat of involuntary physical contact seems much larger for spiders than for maggots or worms. Following this, the interaction of the spiders' contaminating properties and the threat of unwanted physical contact may well constitute the fear of spiders. Germane to 
this, Davey (1993) found that disgust and contamination sensitivity considerably adds to individuals' fear ratings of a novel animal when it is modulated in an interactive fashion by beliefs about being physically contacted or attacked by the animal.

To conclude, the present findings support the idea that contamination-relevant outcome expectancies are critically involved in fear of spiders, thereby adding to the suggestion that spider phobia can be best conceptualised in terms of disease-avoidance processes (e.g., Davey, 1994; de Jong \& Muris, 2002; de Jong et al., 2002; Matchett \& Davey, 1991). The present results seriously question the idea that these prior expectancies are very robust against corrective experiences and add to previous studies (e.g., de Jong \& Merckelbach, 2000) casting doubt on the role of retrospective associative biases in the maintenance of phobic complaints. However, at this stage it would be premature to completely discard the possibility that in addition to UCS expectancy biases, contamination- and/or harm-relevant covariation biases do play a role in spider phobia.

\section{Acknowledgments}

We are grateful to professor Frank Baeyens for his helpful suggestions during the preparation of the present study, to Ingrid Meijners, Nienke Smit, Cathelijne Middendorp, and Lars van Kessel for their contribpution to the development of the present design as well as for taking care for the actual data acquisition, and finally, to Bert Hoekzema for his technical assistance.

\section{References}

Amin, J. M., \& Lovibond, P. F. (1997). Dissociations between covariation bias and expectancy bias for fear-relevant stimuli. Cognition and Emotion, 11, 273-289.

Arkes, H. R., \& Harkness, A. R. (1983). Estimates of contingency between two dichotomous variables. Journal of Experimental Psychology General, 112, 117-135.

Arntz, A., Lavy, E., van den Berg, G., \& van Rijsoort, S. (1993). Negative beliefs of spider phobics: A psychometric evaluation of the spider phobia beliefs questionnaire. Advances in Behaviour Research and Therapy, 15, $257-277$.

Baeyens, F., Crombez, G., De Houwer, J., \& Eelen, P. (1996). No evidence for modulation of evaluative flavor-flavor associations in humans. Learning and Motivation, 27, 200-241.

Boston, A., \& Sharpe, L. (2005). The role of threat-expectancy in acute pain: Effects on attention bias, coping strategy effectiveness and response to pain. Pain, 119, 168-175.

Cavanagh, K., \& Davey, G. C. L. (2000). UCS expectancy biases in spider phobics: Underestimation of aversive consequences following fear-irrelevant stimuli. Behaviour Research and Therapy, 38, 641-651.

Davey, G. C. L. (1992). Classical conditioning and the acquisition of human fears and phobias: A review and synthesis of the literature. Advances of Behaviour Research and Therapy, 14, 29-66.

Davey, G. C. L. (1993). Factors influencing self-rated fear to a novel animal. Cognition and Emotion, 7, 461-471.

Davey, G. C. L. (1994). The disgusting spider: The role of disease and illness in the perpetuation of fear of spiders. Society and Animals, 2 , $17-25$.

Davey, G. C. L., Cavanagh, K., \& Lamb, A. (2003). Differential aversive outcome expectancies for high- and low-predation fear-relevant animals. Journal of Behavior Therapy and Experimental Psychiatry, 34, 117-128.

Davey, G. C. L., \& Dixon, A. L. (1996). The expectancy bias model of selective associations: The relationship of judgements of CS dangerousness, CS-UCS similarity and prior fear to a priori and a posteriori covariation assessments. Behaviour Research and Therapy, $34,235-252$.

de Jong, P. J., \& Merckelbach, H. (2000). Phobia-relevant illusory correlations: The role of phobic responsivity. Journal of Abnormal Psychology, 109, 597-601.

de Jong, P. J., Merckelbach, H., \& Arntz, A. (1991). Illusory correlation, on-line covariation estimates, and electrodermal responding in a (quasi) conditioning paradigm. Biological Psychology, 31, 201-212.

de Jong, P. J., Merckelbach, H., \& Arntz, A. (1995). Covariation bias in phobic subjects: The relationship between a priori expectancy, online expectancy, autonomic responding, and a posteriori contingency judgment. Journal of Abnormal Psychology, 104, 55-62.

de Jong, P. J., Merckelbach, H., Bögels, S. M., \& Kindt, M. (1998). Illusory correlation and social anxiety. Behaviour Research and Therapy, 36, 1063-1073.

de Jong, P., \& Muris, P. (2002). Spider phobia: Interaction of disgust and perceived likelihood of involuntary physical contact. Journal of Anxiety Disorders, 16, 51-65.

de Jong, P., Peters, M., \& Vanderhallen, I. (2002). Disgust and disgust sensitivity in spider phobia: Facial EMG in response to spider and oral disgust imagery. Journal of Anxiety Disorders, 16, 477-493. 
de Jong, van den Hout, M. A., \& Merckelbach, H. (1995). Covariation bias and the return of fear. Behaviour Research and Therapy, 33, 211-213.

de Jong, P. J., Vorage, I., \& van den Hout, M. A. (2000). Counterconditioning in the treatment of spider phobia: Effects on disgust, fear, and valence. Behaviour Research and Therapy, 38, 1055-1069.

Diamond, D., Matchett, G., \& Davey, G. C. L. (1995). The effect of prior fear levels on UCS-expectancy ratings to a fear-relevant stimulus. The Quarterly Journal of Experimental Psychology, 48A, 237-247.

Hamilton, D. L., \& Gifford, R. K. (1976). Illusory correlation in interpersonal perception: A cognitive basis of stereotypic judgments. Journal of Experimental Social Psychology, 12, 392-407.

Huijding, J. \& de Jong, P. J. (in press). Beyond fear and disgust: The role of (automatic) contamination-relevant associations in spider phobia. Journal of Behavior Therapy and Experimental Psychiatry.

Jones, M. K., \& Menzies, R. G. (2000). Danger expectancies, self-efficacy and insight in spider phobia. Behaviour Research and Therapy, $38,585-600$.

Kennedy, S. J., Rapee, R. M., \& Mazurski, E. J. (1997). Covariation bias for phylogenetic versus ontogenetic fear-relevant stimuli. Behaviour Research and Therapy, 35, 415-422.

Matchett, G., \& Davey, G. C. L. (1991). A test of a disease-avoidance model of animal phobias. Behaviour Research and Therapy, 29, 91-94.

McNally, R. J., \& Heatherton, T. F. (1993). Are covariation biases attributable to a priori expectancy biases? Behaviour Research and Therapy, 31, 653-658.

Muris, P., \& Merckelbach, H. (1996). A comparison of two spider fear questionnaires. Journal of Behavior Therapy and Experimental Psychiatry, 27, 241-244.

Öhman, A., Dimberg, U., \& Öst, L.-G. (1985). Animal and social phobias: biological constraints on learned fear responses. In S. Reiss, \& R. R. Bootzin (Eds.), Theoretical issues in behavior therapy (pp. 123-175). New York: Academic Press.

Pauli, P., Montoya, P., \& Martz, G.-E. (1996). Covariation bias in panic-prone individuals. Journal of Abnormal Psychology, 105, 658-662.

Pauli, P., Montoya, P., \& Martz, G-E. (2001). On-line and a posteriori covariation estimates in panic-prone individuals: Effects of a high contingency of shocks following fear-irrelevant stimuli. Cognitive Therapy and Research, 25, 23-36.

Pauli, P., Wiedemann, G., Dengler, W., \& Kühlkamp (2001). A priori expectancy bias and its relation to shock experience and anxiety: A naturalistic study in patients with an automatic implantable cardioverter defebrillator. Journal of Behavior Therapy and Experimental Psychiatry, 32, 159-171.

Pauli, P., Wiedemann, G., \& Montoya, P. (1998). Covariation bias in flight phobics. Journal of Anxiety Disorders, $12,555-565$.

Sawchuk, C. N., Lohr, J. M., Westendorf, D. H., Meunier, S. A., \& Tolin, D. F. (2002). Emotional responding to fearful and disgusting stimuli in specific phobia. Behaviour Research and Therapy, 40, 1031-1046.

Reiss, S. (1980). Pavlovian conditioning and human fear: An expectancy model. Behavior Therapy, 11, 380-396.

Reiss, S. (1991). Expectancy model of fear, anxiety, and panic. Clinical Psychology Review, 11, 141-153.

Szymanski, J., \& O’Donohue, W. (1995). Fear of spiders questionnaire. Journal of Behavior Therapy and Experimental Psychiatry, 26, 31-34.

Tolin, D. F., Lohr, J. M., Sawchuk, C. N., \& Lee, T. C. (1997). Disgust and disgust sensitivity in blood-injection-injury and spider phobia. Behaviour Research and Therapy, 35, 949-953.

Tomarken, A. J., Mineka, S., \& Cook, M. (1989). Fear-relevant selective associations and covariation bias. Journal of Abnormal Psychology, 98, 381-394.

Tomarken, A. J., Sutton, S. K., \& Mineka, S. (1995). Fear-relevant illusory correlations: What types of associations promote judgmental bias? Journal of Abnormal Psychology, 104, 312-326.

Van Overveld, W. J. M., de Jong, P. J., Huijding, J., \& Peters, M. L. (2006). Differential disgust and harm relevant UCS-expectancy bias in spider Phobic individuals: Influence of treatment and its relationship with the return of fear. Manuscript submitted for publication.

Van Overveld, W. J. M., de Jong, P. J., \& Peters, M. L. (2006). Differential UCS expectancy bias in spider phobia: Evidence towards an association of spiders with disgust-outcomes. Journal of Behavior Therapy and Experimental Psychiatry, 37, 60-72.

Wiedemann, G., Pauli, P., \& Dengler, W. (2001). A priori expectancy bias in patients with panic disorder. Journal of Anxiety Disorders, 15, 401-412.

Whittal, M. L., \& Goetsch, V. L. (1997). The impact of panic expectancy and social demand on agoraphobic avoidance. Behaviour Research and Therapy, 35, 813-821. 